Retraction

\title{
Retracted: Use of Geochemical Fossils as Indicators of Thermal Maturation: An Example from the Anambra Basin, Southeastern Nigeria
}

\author{
Journal of Geochemistry \\ Received 18 January 2016; Accepted 18 January 2016 \\ Copyright ( 2016 Journal of Geochemistry. This is an open access article distributed under the Creative Commons Attribution \\ License, which permits unrestricted use, distribution, and reproduction in any medium, provided the original work is properly \\ cited.
}

The paper titled "Use of Geochemical Fossils as Indicators of Thermal Maturation: An Example from the Anambra Basin, Southeastern Nigeria" [1] by Odundun has been retracted at the request of the author as it is based on the study that was carried out by the author's M.S. supervisor, Dr. Matthew E. Nton, who did not consent to the publication of this work.

\section{References}

[1] O. A. Odundun, "Use of geochemical fossils as indicators of thermal maturation: an example from the Anambra Basin, Southeastern Nigeria," Journal of Geochemistry, vol. 2015, Article ID 809780, 11 pages, 2015. 

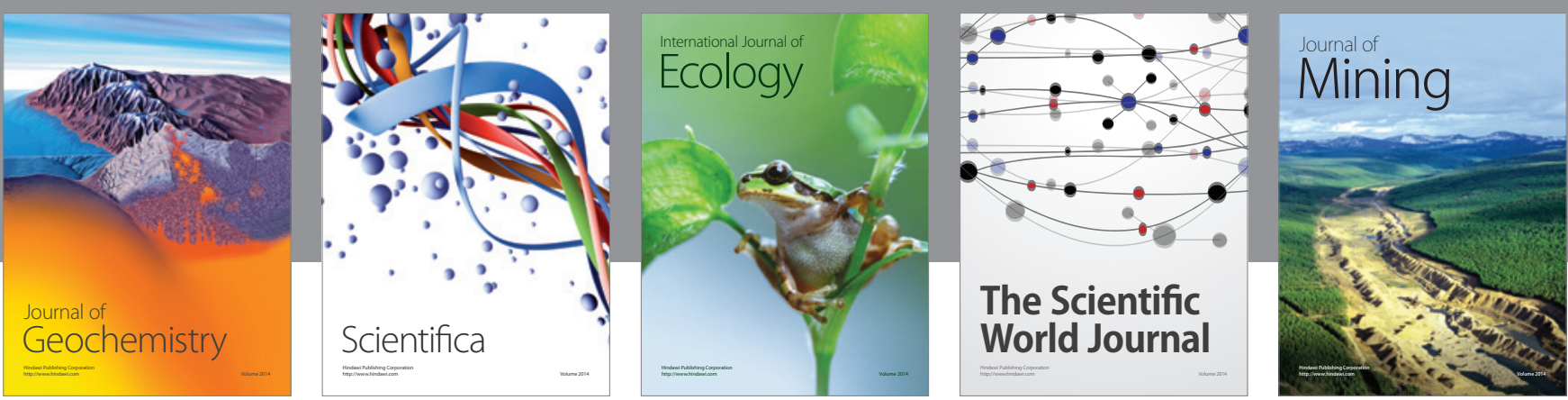

The Scientific World Journal
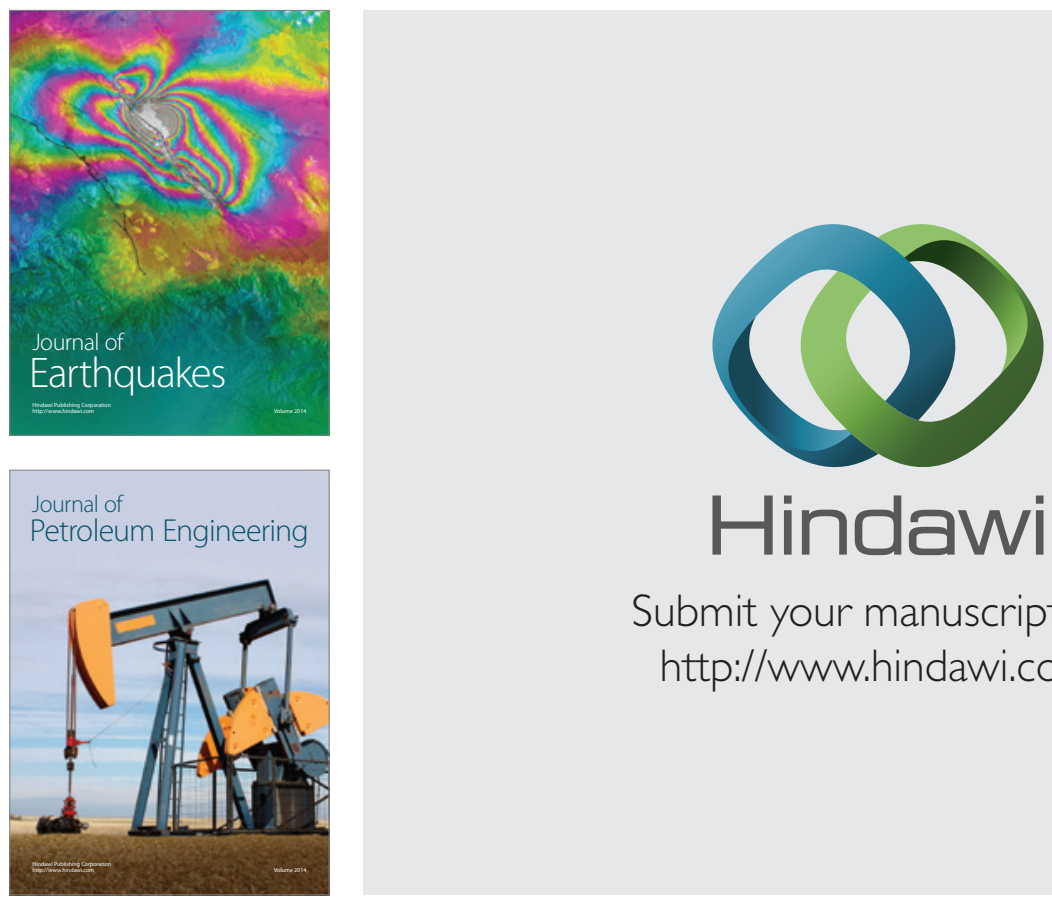

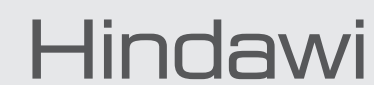

Submit your manuscripts at

http://www.hindawi.com
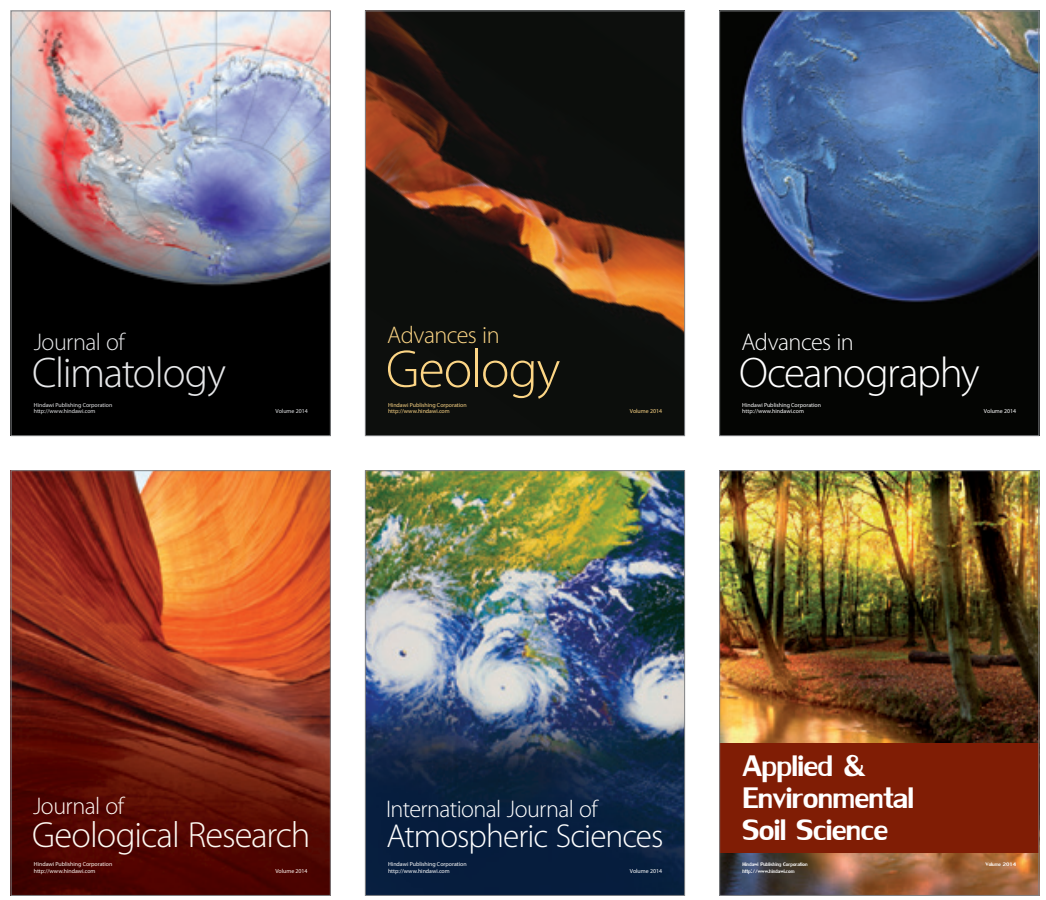
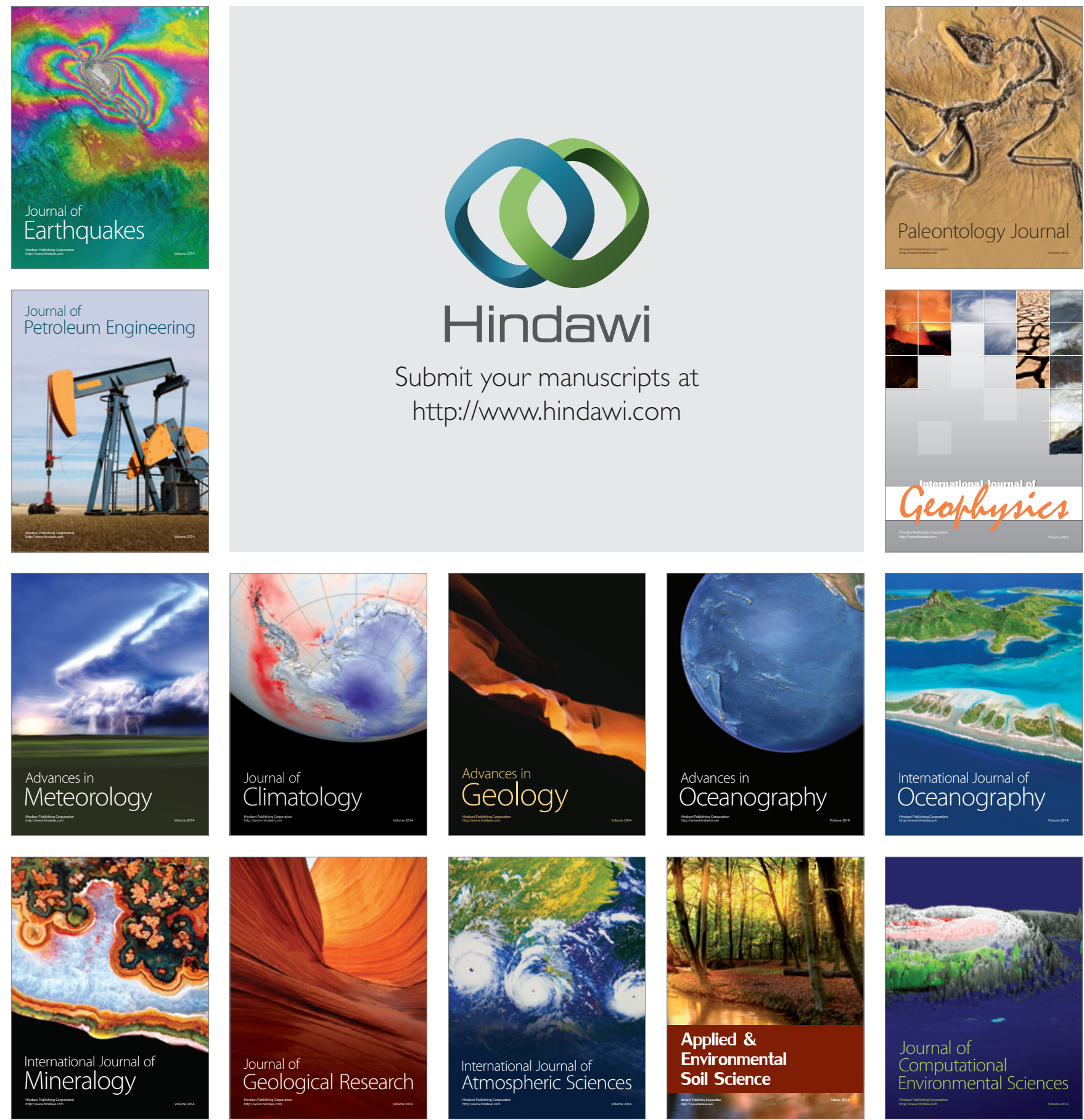